Tropical Journal of Pharmaceutical Research February 2012; 11 (1): 84-90

(C) Pharmacotherapy Group, Faculty of Pharmacy, University of Benin,

Benin City, 300001 Nigeria.

All rights reserved.

\title{
Effect of $\beta$-Glucuronidase on Extraction Efficiency of Silymarin from Human Plasma Samples Using Validated HPLC-UV Analysis
}

\section{Muhammad Usman ${ }^{1 *}$, Mahmood Ahmad ${ }^{1}$, Abdullah Dayo $^{2}$, Asadullah Madni ${ }^{1}$, Liaqat Ali ${ }^{1}$, Muhammad Yousuf ${ }^{1}$, Mahtab Ahmad Khan ${ }^{1}$, Abubakar Munir ${ }^{1}$, Muhammad Sohail ${ }^{1}$ and Arshad Mahmood ${ }^{3}$}

${ }^{1}$ Faculty of Pharmacy and Alternative Medicine, the Islamia University of Bahawalpur-Punjab, ${ }^{2}$ Faculty of Pharmacy, University of Sindh, Jamshoro, ${ }^{3}$ Department of Pharmacy, COMSATS Institute of Information Technology, Abbotabad, Pakistan

\begin{abstract}
Purpose: To investigate the effect of $\beta$-glucuronidase on the extraction efficiency of silymarin (mainly as silybin) from spiked human plasma using a sensitive and reproducible high performance liquid chromatography (HPLC) method.

Methods: The importance of $\beta$-glucuronidase was evaluated by comparing the extraction efficiency of silymarin in $\beta$-glucuronidase-treated and untreated plasma samples. Isocratic HPLC with simple UV detection $(288 \mathrm{~nm})$ was applied to analyze the major silymarin components using Thermo-Electron $C_{18}$ column (200 mm, $4.6 \mathrm{~mm}$ I.D., $5 \mu \mathrm{m}$ particle size). The mobile phase, consisting of methanol and $20 \mathrm{mM}$ potassium dihydrogen phosphate buffer (50:50 v/ $\mathrm{pH} 2.8$ ), was pumped at $1 \mathrm{ml} / \mathrm{min}$.

Results: The mean extraction efficiency was $98.97 \%$ (CV = $1.69 \%)$ for treated and $40.88 \%$ (CV = $2.77 \%$ ) for untreated plasma samples, compared with nominal concentrations.

Conclusion: The studied method showed $60 \%$ reduced extraction efficiency of untreated samples compared to treated samples.
\end{abstract}

Keywords: Silymarin, Silybin, Extraction Efficiency, $\beta$-glucuronidase, HPLC

*Corresponding author: E-mail: minhasiub@hotmail.com; Tel: +92-300-6074181; Fax: +92-62-9255565 


\section{INTRODUCTION}

Silymarin, an extract from the seeds of Silybum marianum (milk thistle), has hepatoprotective and free radical scavenging activities [1-3]. The principal constituent of silymarin is silybin or silibinin, which is a mixture of diastereomers, namely, silybin A and silybin $B(1: 1)$. Other flavonolignans present in silymarin extract are isosilybin $A$, isosilybin $B$, dehydrosilybin, silychristin, silydianin, and a few flavonoids, mainly taxifolin [4]. Silymarin contains silybin as a major component, therefore, most of the studies are based on the assessment of silybin in plasma [5-7]. Silymarin flavonolignans are rapidly metabolized after its oral administration and mainly form glucuronide conjugates. Major biological active components of silymarin are primarily present as glucuronide conjugates in human plasma [8].

A suitable analytical technique should be simple, sensitive, cost-effective and easy to use in analytical laboratories [9,10]. Several analytical methods for the detection and quantification of silymarin flavonolignans in human plasma using HPLC, liquid chromatography mass spectrometry (LC/MS), and liquid chromatography-electrochemical detection have been reported [2-4,8]. These techniques, except HPLC, require several sample processing steps or derivatization [11]. The accuracy and precision of plasma analysis of drugs is based upon their extraction efficiency from plasma matrix.

In previously reported analytical methods, $\beta$ glucuronidase was applied to free the conjugated silymarin components for its easy and reproducible detection because the conjugation and diastereomeric form complicate its quantification from plasma samples [2,3]. Therefore, the present study was aimed at investigating the effect of $\beta$ glucuronidase on extraction efficiency of silymarin from plasma by quantification of its major constituent, silybin. This approach has not been previously reported in the literature, to the best of our knowledge. A previously reported HPLC method [2,3], with slight modification was validated to assess its sensitivity, efficiency, reproducibility, and then applied to analyze $\beta$-glucuronidase-treated and untreated silymarin plasma samples. The ultimate purpose was to explore the feasibility of using $\beta$-glucuronidase to aid the analysis silymarin in human plasma and to report a simple and reliable HPLC-UV analytical method for routine clinical assay and pharmacokinetic studies.

\section{EXPERIMENTAL}

\section{Chemicals and reagents}

Silymarin was a kind gift from Amson Vaccines \& Pharma (Pvt) Ltd, Islamabad, Pakistan. $\quad \beta$-glucuronidase/arylsulfatase, methanol, potassium dihydrogen phosphate, phosphoric acid, sodium acetate, glacial acetic acid, boric acid, potassium chloride, sodium hydroxide and diethyl ether were obtained from Merck-Germany. Double distilled de-ionized water was prepared in our laboratory.

\section{Chromatographic conditions and instrumentation}

Analyses were performed using high performance liquid chromatography (HPLC) with an isocratic pump and variable wavelength detector (Agilent Technologies, series 1100, USA). A reversed phase system was used, consisting of $\mathrm{C}_{18}$ column $(200 \mathrm{~mm}$, $4.6 \mathrm{~mm}$ I.D., $5 \mu \mathrm{m}$ particle size). The mobile phase consisted of a mixture of methanol and $20 \mathrm{mM}$ potassium dihydrogen phosphate buffer $(50: 50, v / v)$, with the $\mathrm{pH}$ of the buffer adjusted to 2.8 with phosphoric acid. The mobile phase was filtered through a $0.45 \mu \mathrm{m}$ membrane filter before use and then pumped at a rate of $1 \mathrm{ml} /$ minute; sample volumes of $100 \mu \mathrm{l}$ were injected, with a total run time of $30 \mathrm{~min}$. The detection was performed at 288 $\mathrm{nm}$. 


\section{Stock solutions and spiking of plasma}

The stock solution of silymarin was prepared fresh by dissolving $50 \mathrm{mg}$ drug in $50 \mathrm{ml}$ of methanol to give a final concentration of 1 $\mathrm{mg} / \mathrm{ml}(1000 \mu \mathrm{g} / 1000 \mu \mathrm{l})$. Working solutions of Silymarin were prepared in mobile phase, by appropriate dilution to obtain solutions with concentrations of $2.5,15,30,62.5,125,250$ and $500 \mu \mathrm{g} / \mathrm{ml}$.

A calibration curve was constructed by spiking $1 \mathrm{ml}$ plasma samples each with $20 \mu \mathrm{l}$ of one of the above mentioned working solutions to produce concentrationsts equivalent to $0.05,0.3,0.6,1.25,2.5,5.0$ and $10 \mu \mathrm{g} / \mathrm{ml}$ of silymarin. Volumes of $100 \mu \mathrm{l}$ were injected and the peak areas were recorded for each concentration. Five sets of samples in human plasma were prepared in duplicate (treated with $\beta$-glucuronidase and untreated samples) at concentrations of $0.05,0.3,0.6$, 2.5 , and $5.0 \mu \mathrm{g} / \mathrm{ml}$.

\section{Sample preparation}

The extraction procedure for $\beta$-glucuronidase treated plasma samples, comprised of $100 \mu \mathrm{l}$ aliquot of acetate buffer $(\mathrm{pH} \mathrm{5.6)}$ and $30 \mu \mathrm{l}$ of $\beta$-glucuronidase (glucuronidase/arylsulfatase mixture, type HP-2, 127,300 units/ml, Helix Pomatia), were added to $100 \mu \mathrm{l}$ plasma samples. The mixtures were incubated with periodical shaking at $37{ }^{\circ} \mathrm{C}$ for $2 \mathrm{~h}$. Thereafter, $200 \mu \mathrm{l}$ of borate buffer $(\mathrm{pH} 8.5)$ and $2.0 \mathrm{ml}$ of diethylether were added, and vortex mixed of $1 \mathrm{~min}$ and centrifuged at $3000 \mathrm{rpm}$ for $2 \mathrm{~min}$. The organic phase was transferred into a clean sample test tube and evaporated under a gentle stream of nitrogen. The dried residues were reconstituted in $130 \mu \mathrm{l}$ of mobile phase, vortexed for $30 \mathrm{~s}$ and centrifuged for $1 \mathrm{~min}$ at $2500 \mathrm{rpm}$. Finally, $100 \mu \mathrm{l}$ of this solution was injected directly into the chromatographic system. The same extraction procedure was applied to prepare untreated plasma samples, except that $\beta$-glucuronidase was not added. Incubation conditions $\left(37^{\circ} \mathrm{C}\right.$ for 2 h) were the same as for the treated samples.

\section{Method validation}

Validation was performed in accordance with the current Food and Drug Administration (FDA) guidelines for biological method validation [12]. The validation run comprised a set of calibration samples, $\beta$-glucuronidasetreated and untreated silymarin plasma samples to determine analytical differences in $\beta$-glucuronidase cleavage of conjugates in human plasma samples. All the validation parameters were compared for treated and untreated plasma samples.

\section{Quantification}

Plasma was collected from human healthy subjects. The study was approved by the Pharmacy Research Ethics Committee (PREC), Faculty of Pharmacy and Alternative Medicine, The Islamia University of Bahawalpur and the guidelines of International Conference on Harmonization $(\mathrm{ICH})$ were followed in the study [13]. The plasma was spiked with prepared working dilutions of silymarin in the range of 0.05 $10.0 \mu \mathrm{g} / \mathrm{ml}$. All spiked samples were extracted and analyzed by HPLC. The calibration curve was constructed by plotting the peak areas versus extracted concentrations of silymarin. Six replicate $(n=$ 6 ) tests were carried out at each level. Linearity of the method was assessed by applying least-squares regression lines. Linearity was expressed by correlation coefficient $\left(r^{2}\right)$, slope and intercept, which were computed using Microsoft Excel 2007 and confirmed by Kinetica ${ }^{\circledR}$ PK/PD version 4.4 .

\section{Precision and accuracy}

Repeated injections $(n=6)$ were performed to assess the repeatability (intra-day) and reproducibility (inter-day) for establishing the precision and accuracy levels. The inter-day and intra-day coefficients of variation were recorded as \%CV. Accuracy was measured as percentage from spiked quantity of drug, using Eq 1.

$\%$ Accuracy $=\left(\mathrm{C}_{\mathrm{o}} / \mathrm{C}_{\mathrm{s}}\right) \times 100$ 
where $\mathrm{C}_{0}$ is the observed concentration (quantitated after extraction) and $\mathrm{C}_{\mathrm{s}}$ is spiked concentration (theoretical quantity added).

\section{Limit of detection (LOD) and limit of quantitation (LOQ)}

Limit of detection (LOD) and limit of quantitation (LOQ) were determined to establish the sensitivity of the analytical method. LOD is repeatedly detected lowest analyte concentration while LOQ refers to reliably quantitated lowest concentration under specified experimental conditions. LOD and LOQ were determined by repeatedly injecting $(n=6)$ the samples from the lowest to the highest concentration accurately and their precise drug concentrations determined.

\section{Extraction efficiency}

Extraction efficiency was determined by adding known concentrations of silymarin to prepare spiked solutions and comparing their responses (peak areas) to that of pure standard solutions (non-extracted). Three sample batches were prepared and subjected to measure their extraction efficiency. These sample batches comprised of the following silymarin concentration ranges: Batch-01 $(0.05-10.0 \mu \mathrm{g} / \mathrm{ml}$, same as for calibration curve), Batch-02 (0.05, 0.3, 0.6, 2.5, and 5.0 $\mu \mathrm{g} / \mathrm{ml}$, for treated samples), and Batch-03 $(0.05,0.3,0.6,2.5$, and $5.0 \mu \mathrm{g} / \mathrm{ml})$, for nontreated samples).

\section{Freeze thaw stability}

Stability studies of plasma samples (for both spiked plasma and drug free blank plasma sample which served as control) were performed in three freeze-thaw cycles (cycle 0 , cycle 1 , cycle 2 and cycle 3 and each cycle consisted of $72 \mathrm{~h}$ ). All the samples were stored at $-70{ }^{\circ} \mathrm{C}$ in ultra-low freezer (Sanyo, Japan) for $72 \mathrm{~h}$, and freeze-thaw stability was determined as percent recovery $(n=3)$. The stored samples were withdrawn from the ultra-low freezer and allowed to thaw at room temperature in ordinary light. The thawed samples were assayed for silymarin content.

\section{Statistical analysis}

Statistical analysis was performed to determine significant differences (if any) between the extracted silymarin contents of treated and untreated plasma samples. The data were analyzed using MedCal software, and significant difference was set at $95 \%$ confidence level.

\section{RESULTS}

\section{Linearity, precision and accuracy}

The linearity of the method was investigated within the concentration range of $0.05-10$ $\mu \mathrm{g} / \mathrm{ml}$. The applied method showed good linearity under the described optimum chromatographic conditions. The linear regression equation was $y=47.09 x+16.48$ with a correlation coefficient $\left(\mathrm{R}^{2}\right)$ of 0.9909 . Retention times were 13.296 and 14.895 for silybin $A$ and silybin $B$, respectively. A representative chromatogram is shown in Fig 1.

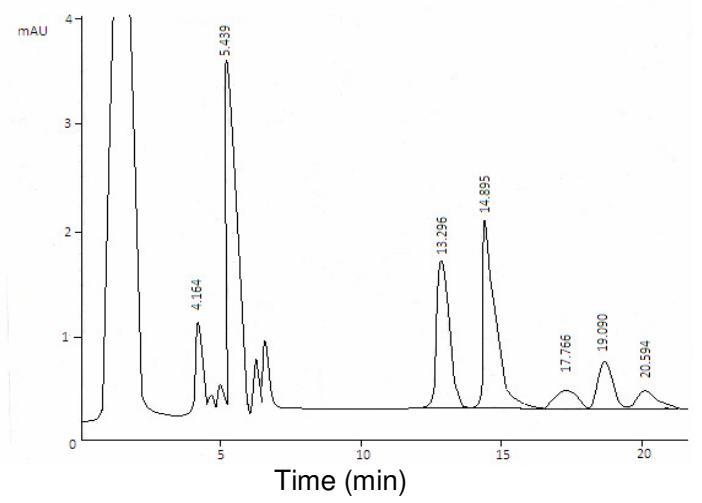

Fig 1: Representative chromatogram of silymarin in treated plasma

Intra-day and inter-day precision and accuracy results for the method are shown in Table 1. Intra-day precision of silymarin (at low, mid and highest concentration levels of $0.05,1.25$ and $5 \mu \mathrm{g} / \mathrm{ml}$ ) ranged from $1.6-2.3$ $\%$, expressed as percent coefficient of variation $(\% \mathrm{CV})$, while accuracy was $>99 \%$. Inter-day precision and accuracy were 1.8 $2.8 \%$ (expressed as \%CV) and > $98 \%$, respectively. \%CV was within the acceptable 
Table 1: Intra-day and inter-day precision and accuracy of treated samples

\begin{tabular}{lccc}
\hline $\begin{array}{l}\text { Nominal } \\
\text { concentration }\end{array}$ & Concentration found & Precision (\%CV) & Accuracy (\%) \\
\hline Intra-day & & & \\
0.05 & $0.048 \pm 0.001$ & 2.292 & 96.00 \\
1.25 & $1.249 \pm 0.021$ & 1.697 & 99.92 \\
10 & $9.994 \pm 0.171$ & 1.711 & 99.94 \\
Inter-day & & & \\
0.05 & $0.047 \pm 0.001$ & 2.766 & 94.00 \\
1.25 & $1.237 \pm 0.022$ & 1.811 & 98.96 \\
10 & $9.868 \pm 0.214$ & 2.169 & 98.68 \\
\hline
\end{tabular}

Table 2: Comparative silymarin (as silybin) concentrations of treated and untreated plasma samples $(n=6)$

\begin{tabular}{lcc}
\hline $\begin{array}{l}\text { Nominal } \\
\text { concentration } \\
(\mu \mathrm{g} / \mathrm{ml})\end{array}$ & $\begin{array}{c}\text { Conc. found in treated } \\
\text { samples (Mean } \pm \text { SD) } \\
(\mu \mathrm{g} / \mathrm{ml})\end{array}$ & $\begin{array}{c}\text { Conc. Found in untreated } \\
\text { samples (Mean } \pm \mathrm{SD})(\mu \mathrm{g} / \mathrm{ml})\end{array}$ \\
\hline 0.05 & $0.049 \pm 0.0011$ & $\mathrm{ND}^{*, \mathbf{s}}$ \\
0.30 & $0.297 \pm 0.0037$ & $\mathrm{ND}^{\mathbf{s}}$ \\
0.60 & $0.590 \pm 0.0115$ & $0.2402 \pm 0.0113^{\mathbf{s}}$ \\
2.5 & $2.495 \pm 0.0614$ & $0.9935 \pm 0.0211^{\mathbf{s}}$ \\
5 & $4.986 \pm 0.139$ & $2.143 \pm 0.0316^{\mathbf{s}}$ \\
$\% \mathrm{CV}$ & 1.689 & 2.768 \\
Extraction efficiency & $98.97 \%$ & $40.88 \%$ \\
\hline
\end{tabular}

${ }^{*}$ Not detected; $s$ = significant difference between drug concentration of treated and non-treated samples $(p<0.05)$

limit of $20 \%$ for lower limit of quantification and $15 \%$ for upper limit of quantification [12].

\section{Limits of detection (LOD) and of quantitation (LOQ)}

LOD and LOQ for silymarin samples (treated samples) were 0.028 and $0.05 \mu \mathrm{g} / \mathrm{ml}$, respectively. For $L O Q$, coefficient of variation was $2.3 \%(n=6)$.

\section{Extraction efficiency}

Extraction efficiency was determined as the mean extraction efficiency (mean $\pm S D$ ) of treated samples $(n=6)$. The results obtained are shown in Table 2. The mean extraction efficiency at nominal concentrations of 0.05 , $0.30,0.60,2.5$ and $5.0 \mu \mathrm{g} / \mathrm{ml}$ was $98.97 \%$ for treated silymarin plasma samples and 40.88 $\%$ for untreated samples. At these concentration levels, coefficient of variation
(\%CV) was 1.689 and $2.768 \%$ for treated and untreated samples, respectively.

The studied method showed approximately $60 \%$ reduced extraction efficiency compared with untreated samples.

\section{Freeze-thaw stability}

Freeze-thaw stability was determined as percent recovery (mean $\pm S D$ ) compared to nominal concentrations in plasma samples. The difference in nominal value was in range of -1.6 to $-7.8 \%$ at the completion of the third freeze-thaw cycle (Table 3 ).

\section{DISCUSSION}

The rapid and simple analysis of compound drug with complex constituents (plant based drugs) is often difficult to carry out with reasonable accuracy and precision. Analytical quantification of such drugs 
Table 3: Freeze-thaw stability in plasma for silymarin (treated samples).

\begin{tabular}{|c|c|c|c|c|c|c|c|c|}
\hline \multirow{3}{*}{$\begin{array}{c}\text { Parameter } \\
\text { Nominal conc. }\end{array}$} & \multicolumn{8}{|c|}{ Freeze-Thaw Cycles } \\
\hline & \multicolumn{2}{|c|}{$\begin{array}{c}\text { Cycle } 0 \\
\mu \mathrm{g} / \mathrm{ml}\end{array}$} & \multicolumn{2}{|c|}{$\begin{array}{l}\text { Cycle } 1 \\
\mu \mathrm{g} / \mathrm{ml}\end{array}$} & \multicolumn{2}{|c|}{$\begin{array}{c}\text { Cycle } 2 \\
\mu \mathrm{g} / \mathrm{ml}\end{array}$} & \multicolumn{2}{|c|}{$\begin{array}{c}\text { Cycle } 3 \\
\mu \mathrm{g} / \mathrm{ml}\end{array}$} \\
\hline & 2.0 & 10 & 2.0 & 10 & 2.0 & 10 & 2.0 & 10 \\
\hline Mean $\pm S D$ & $\begin{array}{c}1.973 \\
\pm 0.0255\end{array}$ & $\begin{array}{c}9.887 \\
\pm 0.136\end{array}$ & $\begin{array}{c}1.941 \\
\pm 0.0281\end{array}$ & $\begin{array}{c}9.739 \\
\pm 0.174\end{array}$ & $\begin{array}{c}1.884 \\
\pm 0.0288\end{array}$ & $\begin{array}{r}9.373 \\
\pm 0.180\end{array}$ & $\begin{array}{c}1.839 \\
\pm 0.0292\end{array}$ & $\begin{array}{c}9.111 \\
\pm 0.182\end{array}$ \\
\hline CV (\%) & 1.292 & 1.375 & 1.448 & 1.787 & 1.529 & 1.920 & 1.588 & 1.997 \\
\hline \%Difference & - & - & -1.622 & -1.497 & -4.511 & -5.199 & -6.792 & -7.849 \\
\hline
\end{tabular}

becomes more complicated when they are analyzed in biological fluids such as human plasma [14-15]. This might be because of interference caused by plasma protein binding as well as difficult in recovering drug from plasma matrix. The test method is a slightly modification of previously reported methods [2,3] and has been validated to analyze silymarin in human plasma irrespective of the dosage forms.

The present method was successfully validated to authenticate its sensitivity, reproducibility, precision and accuracy in order to explore the effect of $\beta$-glucuronidase on the recovery of silymarin from plasma samples. Various mobile phases of acetonitrile and methanol with different buffer solutions (acetate, citrate and phosphate buffer) were tested in preliminary experiments to ascertain the optimum for maximum separation, sensitivity and reproducibility. The mobile phase of methanol: phosphate buffer $(50: 50, v / v)$ at $\mathrm{pH}$ 2.8 with $1 \mathrm{ml} / \mathrm{min}$ flow rate provided optimum separation. The intra-day and inter-day variability of the studied method was minimum $(<2.3 \%)$ at low, mid and highest concentrations of silymarin of $0.05,1.25$ and $5 \mu \mathrm{g} / \mathrm{ml}$, respectively, while accuracy was > $99 \%$.

This validated and optimized method was applied to explore the effect of $\beta$ glucuronidase in the extraction recovery of silymarin from human plasma. The samples extracted after treatment with $\beta$ glucuronidase showed an apparent difference in silymarin quantitation with high sensitivity and better response (peak areas and heights) as compared to non-treated samples. The mean extraction efficiency was $98.97 \%$ (\%CV as $1.689 \%$ ) for treated and $40.88 \%$ (\%CV as $2.768 \%$ ) for non-treated plasma samples when compared with nominal concentrations. The biological fluids such as plasma, urine are a complex mixture of biomolecules that can interfere with the analysis of drugs by reducing extraction efficiency or by complicating the separation of analytes at the selected UV wavelength. Efficient extraction process during sample preparation can recover specific analytes of interest by treating with suitable precipitating agents and/or compounds which make the spiked drug free from plasma matrix.

$\beta$-glucuronidase is used in HPLC method development process for silymarin analysis and, in this method can be applied to quantify the silymarin in plasma samples after oral administration. These samples are treated with $\beta$-glucuronidase to cleave the major glucuronide conjugates (substrate for $\beta$ glucuronidase) of silymarin to free the drug, and this make its detection and quantitation easy.

Silymarin conjugates with glucuronide and sulfate both in-vitro and in-vivo [8]. The glucuronidation was extensive conjugation because of the fact that glucuronic acid is readily available, derived from glucose and is stored in the form of glycogen. Agents with functional groups such as hydroxyl, amino, carboxyl and sulfhydryl have a high binding affinity for glucuronic acid. Glucuronidation is catalyzed by UDP-glucuronosyltransferases, which are located in endoplasmic reticulum, and most dominant enzymes [16]. In our study, we found decreased response to silymarin 
detection and quantification in untreated samples, as the silymarin was completely undetected at 0.05 and $0.30 \mu \mathrm{g} / \mathrm{ml}$. The reduced silymarin recovery from spiked plasma (untreated) can be attributed to gucuronidation or sulfation following incubation. $\beta$ glucuronidase treatment cleaved these conjugates which increased free drug concentration and extraction recovery from spiked plasma.

\section{CONCLUSION}

The studied method is suitable for accurate, precise and reproducible quantification of silymarin without interference from endogenous components of plasma. This method can be applied for the pharmacokinetic analysis and therapeutic monitoring of silymarin in human plasma with high sensitivity and resolution, by treating plasma samples with $\beta$-glucuronidase.

\section{ACKNOWLEDGEMENT}

The authors acknowledge the collaborative support of Amson Vaccines and Pharma (Pvt) Ltd. Islamabad, Pakistan.

\section{REFERENCES}

1. Morazzoni $P$, Bombardelli E. Silybum marianum (Carduus marianus). Fitoterapia 1995; 64: 342

2. Rickling $B$, Hans $B$, Kramarczyk $R$, Krumbiegel $G$, Weyhenmeyer $R$. Two high-performance liquid chromatographic assays for the determination of free and total silibinin diastereomers in plasma using column switching with electrochemical detection and reversed-phase chromatography with ultraviolet detection. J Chromatogr B 1995; 670: 267-277

3. Kim YC, Kim EJ, Lee ED, Kim JH, Jang SW, Kim YG, Kwon JW, Kim WB, Lee MG. Comparative bioavailability of silibinin in healthy male volunteers. Int J Clin Pharmacol Ther 2003; 41: 593-596

4. Kvasnickaa F, Bibab B, Sevcika R, Voldricha $M$, Kratka J. Analysis of the active components of silymarin. J Chromatogr A 2003; 990: 239-245
5. Wei W, Wang Y, Li Q. Enhanced bioavailability of silymarin by self-microemulsifying drug delivery system. Eur J Pharm Biopharm 2006; 63: 288-294

6. Mascher $H$, Kikuta $C$, Weyhenmeyer $R$. Diasteriomeric separation of free and conjugated silibinin in plasma by reversed phase HPLC after specific extraction. J Liq Chromatogr 1993; 16: 2777-2789

7. Morrazzoni $P$, Magistretti MJ, Giachetti $C$, Zanolo G. Comparative bioavailability of silipide, a new flavanolignan complex in rats. Eur J Drug Metab Pharmacokinet 1992; 17: 39-44

8. Zhiming W, Dumas TE, Schrieber SJ, Hawke RL, Fried MW, Smith PC. Pharmacokinetics and Metabolic Profile of Free, Conjugated, and Total Silymarin Flavonolignans in Human Plasma after Oral Administration of Milk Thistle Extract. Drug Metab Dispos 2008; 36: 65-72

9. Rodney $R$, Khazaeli $L M B$, Kenneth Dillon $H$. Development of an HPLC method for simultaneous analysis of Five Antineoplastic Agents. App Occ Envir Hyg 2003; 18: 109-119

10. Alsarra IA, Alarifi $M N$, Validated liquid chromatographic determination of 5fluorouracil in human plasma. J Chromatogr $B$ 2004; 804: 435-439

11. Coe RA, Earl RA, Johnson TC, Lee JW. Determination of 5-fluorouracil in human plasma by a simple and sensitive reversedphase HPLC method. J Pharm Biomed Anal 1996; 14: 1733-1741

12. US Food and Drug Administration [Homepage on the internet]. Center for Drug Evaluation and Research (CDER), 2001 [cited 2011 Jan 10]. Available from: http://www.fda.gov/cder/ guidance/index.htm.

13. International Conference on Harmonization $\mathrm{ICH}$ [Homepage on the internet]. Guidlines for Good Clinical Practices, 1996 [cited 2011 Jan 11]. Available from: http://www.ich.org.htm.

14. Ahmad I, Aqil F, Ahmad F, Owais M. Modern Phytomedicine, turning medicinal plants into drugs, herbal medicines: prospects and constraints. WILEY-VCH, 2006; pp 59-77

15. Ernst E. Herbal Medicine. A Concise Overview for Professionals. Loew D, Schroedter A, Eds. Quality and Standardization of Herbal Medicinal Products, Elsevier Health Sciences; 2000; pp 59-68

16. Kaushik R, Levine B, LaCourse WR. A brief review: HPLC methods to directly detect drug glucuronides in biological matrices (Part I). Anal Chim Acta 2006; 556: 255-266. 